\title{
Statistics spark dismissal suit
}

\section{Fired researcher's allegations of misconduct prompt university to investigate vaccine trial.}

For those in the audience, the talk would have seemed routine. Speaking to the American Society of Clinical Oncologists, David O'Neill, an immunologist running a vaccine laboratory at the New York University (NYU) Cancer Institute, presented results from a clinical trial of a prospective anticancer vaccine. But less than a year after that June 2009 presentation, in April 2010, O'Neill was fired from his job, in part, he alleges, because of his insistence at being the one to give that talk - and the unvarnished account he delivered of the trial's results.

These are among the complaints laid out in a wrongful dismissal suit that O'Neill launched against his former employer last month. He further contends that he was fired after reporting that his supervisor and former collaborator, Nina Bhardwaj, engaged in scientific misconduct. In documents filed in the New York Supreme Court, O’Neill alleges that Bhardwaj, who had a financial interest in the trial's outcome, sought to improve the appearance of the results by changing the statistical method used to analyse the data. William Carroll, the institute's director, says Bhardwaj did not change statistical approaches after she was unblinded to the study, although the suit has prompted the university to investigate the misconduct accusation. Both O'Neill and Bhardwaj - who still works at NYU - declined to speak to Nature while litigation is under way. Their disagreement underscores the power and perils of clinical-trial statistics.

Most biostatisticians agree that the preferred approach to analysing clinical-trial results is to pick a statistical method beforehand and stick with it. Otherwise, according to Janet Wittes, head of Statistics Collaborative, a Washington DCbased company that designs and analyses clinical trials, you are "betting on a horse after the race is over".

"Having looked at the data before you decide what to do, you can increase the chances of getting the result you want," Wittes says. All too often, she says, confidence in a therapy will lead researchers to change their approach. "They believe in their experiment and they say 'obviously this is what I should have done because it shows what I know is true."' Whether or not such thinking occurred at NYU, O'Neill's case may hinge on the adequacy of the university's

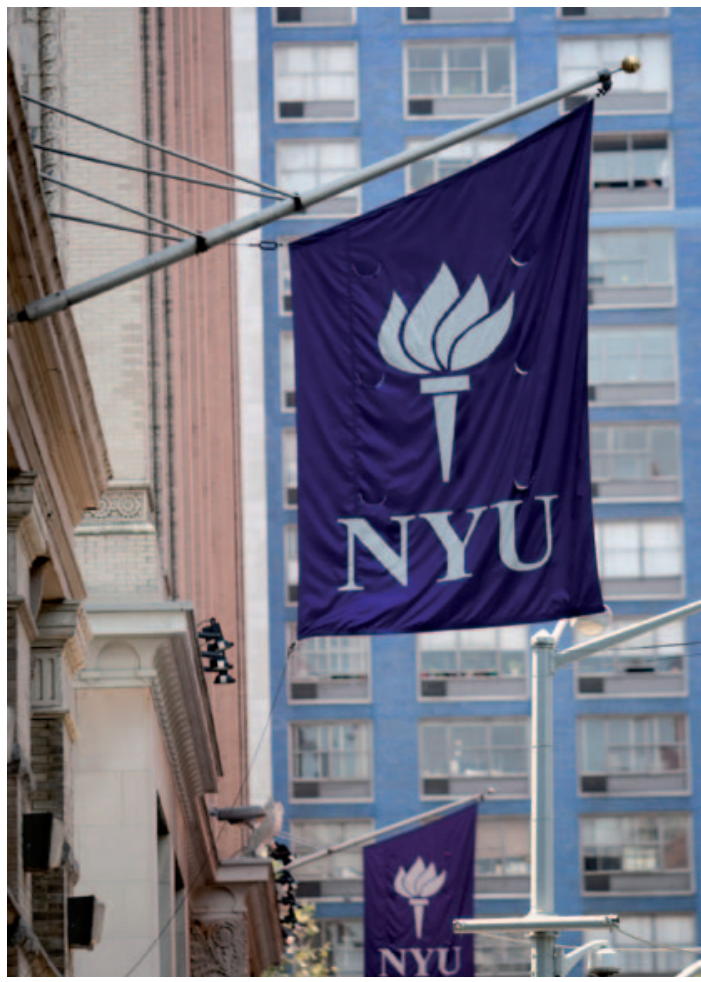

New York University has begun a misconduct investigation.

including Bhardwaj, "desired the most polished presentation possible" and so they worked with O'Neill “to optimize his delivery of the work".

O'Neill accuses Bhardwaj of trying to "spin" the results of the trial in a manuscript they were preparing to submit to Nature Medicine. His complaint alleges that she wanted to create "a more favourable appearance for the dendritic-cell vaccine" by using new analysis that minimized the differences between the two vaccines. O'Neill called the approach "flawed and misleading and therefore invalid" in a 26 October 2009 e-mail to Bhardwaj and other co-authors. After some wrangling, the paper was submitted with analyses favoured by both parties and O'Neill did not remove his name from it. (The paper was later rejected by Nature Medicine, with an opportunity to resubmit after revisions.)

\section{Statistical wrangles}

O'Neill and Bhardwaj's relationship apparently deteriorated over the rest of 2009 and early 2010. On 25 April 2010, O’Neill was fired for "unprofessional behaviour". The dismissal letter, from Carroll, refers to O'Neill's conduct when dealing with response to what began as a debate over data analysis.

The dispute centres on a dendritic-cell vaccine that Bhardwaj was testing for its ability to raise an immune response against melanoma. Such vaccines use cells isolated from the patient, which are taught to recognize tumour-associated antigens and then injected back into the patient to teach the rest of the immune system to attack the tumour. The vaccines are costly and complex "The data is the
data and everybody
signed off on this." to develop, and the data suggested that this one was worse at raising an immune response than a vaccine formulated with an inexpensive mineral-oil-based adjuvant.

Bhardwaj was initially blinded to the data because she holds a patent related to the dendritic-cell vaccine. O’Neill claims that she was disappointed with the results after becoming unblinded. He alleges that, in an effort to control how the results were presented, Bhardwaj announced that she would present the results herself at the American Society of Clinical Oncology meeting, despite the meeting's policy that first authors give talks.

Carroll says senior authors on the study, an outside visitor to the lab and to a subsequent phone conversation with Carroll in which O'Neill's voice "rose in anger". O'Neill alleges that his dismissal was retaliation for his accusations of misconduct.

NYU spokesperson Lisa Greiner says that the quarrel between O'Neill and Bhardwaj on the statistical methods was considered at the time to be an academic disagreement. "The lawsuit against us was the first time misconduct was brought up," she says.

Carroll denies that Bhardwaj changed the original statistical approach after she was unblinded. "When David brought his concerns about the statistical methodology to the table, we convened a meeting of all authors and went forward with three different statistical methods, including the one he promoted," he says. "There was no misconduct."

And all the methods, he points out, came to the same conclusion: the mineral-oil-based vaccines were better. So how Bhardwaj's conduct amounts to misconduct "mystifies" Carroll. "The data is the data and everybody signed off on this", he says.

Emma Marris 